\title{
ELECTRON INDUCED DEPASSIVATION OF H AND D TERMINATED
} $\mathrm{Si}_{\text {SiO2 }}$ INTERFACES

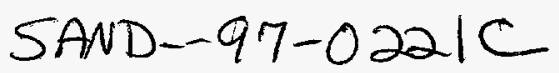

R. A. B. DEVINE*, W. L. WARREN**, K. VANHEUSDEN**, C. MOURRAIN*, M-J. BOUZID*

* France Télécom - CNET, BP 98, 38243 Meylan, France

** Sandia National Laboratories, Albuquerque, NM 87185-1349

ABSTRACT

$$
\begin{aligned}
& \text { CONF }-961202-52 \text { JAN } 34997 \\
& \text { OSTI }
\end{aligned}
$$

We have performed electron spin resonance and electrical measurements on $\mathrm{SiO}_{2} / \mathrm{Si}$ structures subjected to anneals in $5 \% \mathrm{H}_{2} / \mathrm{N}_{2}$ or $5 \% \mathrm{D}_{2} / \mathrm{N}_{2}$ gases and subsequently injected with electrons using corona ions and ultra-violet radiation. Threshold voltage and transconductance measurements have also been made on $0.25 \mu \mathrm{m}$ metal-oxide-semiconductor transistors subjected to $400{ }^{\circ} \mathrm{C}$ anneals in the same gases and subsequently aged by hot electron injection. The electrical data on $\mathrm{SiO}_{2} / \mathrm{Si}$ structures indicates that the density of interface states increases as a result of electron injection but that there are only minor differences between $H$ and $D$ passivated interfaces. The data on $\mathrm{Pb}$, trivalent Si dangling bond, centers at the same interfaces observed by electron spin resonance is insufficiently accurate to enable us to observe any significant differences. The hot electron injection experiments on transistors, consistent with other authors, indicate that, for the limited number of measurements we have made, the transistor ageing resulting from the generation of interface states is significantly reduced for devices annealed in the D containing gas as compared to those annealed in the $\mathrm{H}$ containing gas. The origins of some potential differences in annealing behaviour between the $\mathrm{SiO}_{2} / \mathrm{Si}$ structures and the $0.25 \mu \mathrm{m}$ transistors are suggested.

\section{INTRODUCTION}

It is well known that annealing in $\mathrm{H}$ containing gases will substantially reduce the density of interface states at the $\mathrm{SiO}_{2} / \mathrm{Si}$ interface and the process has been used in $\mathrm{Si}$ based technology for many years for this very reason. Generally, one assumes that the role of hydrogen is to passivate defects such as the $\mathrm{Si}$ dangling bond $(\mathrm{Pb}$ center) or strained $\mathrm{Si}-\mathrm{O}$ bonds at the interface. Various authors [1-3] have demonstrated that the $\mathrm{H}$ can be suitably replaced by $\mathrm{D}$ with no particular difference in behavior. This is not surprising, intuitively speaking, since generally the $\mathrm{X}-\mathrm{H}$ bond energy (where $\mathrm{X}$ is another bonded element) differs from the $\mathrm{X}-\mathrm{D}$ bond energy by only one or two percent [4] and this due essentially to differences in the zero point energy resulting from the nuclear mass difference. One therefore anticipates that the interfacial Si-H and Si-D bond energies are little different. Electron spin resonance (ESR) studies of the evolution of the $\mathrm{Pb}$ center density resulting from thermally induced desorption of $\mathrm{H}$ and $\mathrm{D}$ from passivated $\mathrm{Si}$ (111) interfaces [1] confirm this hypothesis, the activation energies for release of $\mathrm{H}$ or $\mathrm{D}$ are found to be essentially the same and $\sim 2.56 \mathrm{eV}$. The Arrhenius pre-exponential factor for $\mathrm{D}$ is, however, smaller by $\sim 0.82$ for $\mathrm{D}$ dissociation, a ratio which can be interpreted as essentially due to a square root of the mass difference.

On the basis of the above observations it is surprising that recent measurements [5] on hot electron injection induced ageing of metal-oxide-semiconductor field effect transistors (MOSFET's) suggest that if the usual forming gas $\left(5 \% \mathrm{H}_{2}\right.$ in $\left.\mathrm{N}_{2}\right)$ anneal is substituted by one containing $\mathrm{D}_{2}$ in the place of the $\mathrm{H}_{2}$, then the lifetime of the devices is significantly enhanced. The enhancement factor is of the order of fifty times. Such an increase in lifetime obtained simply by changing the anneal gas is clearly of utmost interest for technology. The interest is not because one might wish to extend the times from the usual 10 years to 500 but because it might enable some relaxation of the strict processing conditions required to obtain the 10 year criterion in the first case. It is important to reiterate that the MOSFET lifetime studies were carried out a) using electron injection to release the $\mathrm{H}$ or $\mathrm{D}$ as opposed to thermal stimulation and $\mathrm{b}$ ) the structures were "confined", $\mathrm{Si}_{2} \mathrm{SiO}_{2} / \mathrm{Si}$ and not the open $\mathrm{SiO}_{2} / \mathrm{Si}$ kind used in thermal dissociation studies.

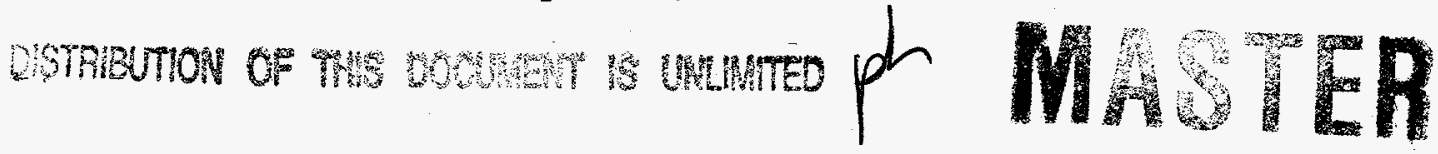




\section{DISCLAIMER}

This report was prepared as an account of work sponsored by an agency of the United States Government. Neither the United States Government nor any agency thereof, nor any of their employees, make any warranty, express or implied, or assumes any legal liability or responsibility for the accuracy, completeness, or usefulness of any information, apparatus, product, or process disclosed, or represents that its use would not infringe privately owned rights. Reference herein to any specific commercial product, process, or service by trade name, trademark, manufacturer, or otherwise does not necessarily constitute or imply its endorsement, recommendation, or favoring by the United States Government or any agency thereof. The views and opinions of authors expressed herein do not necessarily state or reflect those of the United States Government or any agency thereof. 


\section{DISCLAMMER}

Portions of this document may be illegible in electronic image products. Images are produced from the best available original document. 
In the following, we report the results of similar measurements on $0.25 \mu \mathrm{m}$ MOSFETs to those performed previously on $0.5 \mu \mathrm{m}$ devices [5] thereby extending the range of study of validity of the observations. We have also performed electrical (capacitance - voltage) measurements and ESR on open $\mathrm{SiO}_{2} / \mathrm{Si}$ structures which we injected with electrons with the assistance of positive corona ions on the oxide surface and sub-bandgap (oxide) ultraviolet radiation. These experiments were devised to try to obtain more "atomic level" information on the electron induced $\mathrm{H}$ and $\mathrm{D}$ depassivation process.

\section{EXPERIMENT}

In order to maximise the numbers of $\mathrm{Pb}$ centers and interface states for the open structure measurements $40 \mathrm{~nm}$ thick dry oxides were grown at $950^{\circ} \mathrm{C}$ on (111) oriented 2" Si wafers. For the ESR measurements the wafer resistivity was $>1000 \Omega \mathrm{cm}$ whilst it was $6-9 \Omega \mathrm{cm}$ type $\mathrm{n}$ for the electrical (interface state density) measurements. The backface oxide of the oxidised wafers was removed using the floatation technique together with an HF acid attack for the electrical measurement samples whilst it was not removed on ESR samples. All of the samples were annealed for several days at $700^{\circ} \mathrm{C}$ in a vacuum of $\sim 10^{-7}$ torr. Some of these were used as vacuum annealed references whilst others were interface passivated by annealing in an atmosphere of either $5 \% \mathrm{H}_{2}$ in $\mathrm{N}_{2}$ or $5 \% \mathrm{D}_{2}$ in $\mathrm{N}_{2}$ at $400{ }^{\circ} \mathrm{C}$ for 30 minutes. ESR experiments were carried out using a Bruker $\mathrm{X}$ band spectrometer. The density of $\mathrm{Pb}$ centers was measured directly in the vacuum annealed samples and as a function of electron injection in $\mathrm{D}_{2}$ and $\mathrm{H}_{2}$ annealed samples. Electron injection from the Si substrate was performed by depositing positive corona ions on the oxide surface and illuminating the oxide with $<5.5 \mathrm{eV}$ radiation from a mercury arc lamp. Electrical measurements on the open structure samples were made using a mercury bead apparatus to form the gate electrode. Samples were again either the vacuum annealed, $\mathrm{H}_{2}$, or $\mathrm{D}_{2}$ annealed samples subjected to electron injection. The same process of corona ions/ultraviolet light was used to provide the electron injection. Electrical measurements were carried out at $1 \mathrm{MHz}$ and the Terman technique was used to deduce the interface state density from the difference between the mid-gap voltage and the flat-band voltage of the oxide capacitor [6].

$\mathrm{n}$ channel MOSFETs with $0.25 \mu \mathrm{m}$ channel lengths and $10 \mu \mathrm{m}$ widths were obtained [7] with $5-\mathrm{nm}$ thick gate oxides and polycrystalline $\mathrm{Si} / \mathrm{TiSi} 2 / \mathrm{W}$ gates. To remove any "undesirable" passivation present due to the processing steps, the transistors were first outgassed in a vacuum of $10^{-7}$ torr for at least 48 hours at $550^{\circ} \mathrm{C}$ prior to being annealed at $400^{\circ} \mathrm{C}$ for 30 minutes in $\mathrm{D}_{2}$ or $\mathrm{H}_{2}$ containing forming gas. Following the annealing sequences the samples were subjected to hot electron stressing. First, for a given drain-source voltage $\left(\mathrm{V}_{\mathrm{ds}}\right)$ value, the gate-source voltage $\left(\mathrm{V}_{\mathrm{gs}}\right)$ giving the maximum substrate current was ascertained, this procedure was carried out for a range of $\mathrm{V}_{\mathrm{ds}}$ values. Then $\mathrm{V}_{\mathrm{ds}} / \mathrm{V}_{\mathrm{gs}}$ couples were chosen and the transistors stressed for varying times under these conditions. The device lifetime for a given couple was determined to be the stress time at which a $10 \%$ variation in the source-drain current measured in the linear region ( $\mathrm{I}_{\left.\mathrm{d}_{(\mathrm{in})}\right)}$ occured. From a plot of the different stress times as a function of $1 / \mathrm{V}_{\mathrm{ds}}$ extrapolated to the device working potential (for us, $\mathrm{V}_{\mathrm{ds}}=2.5 \mathrm{~V}$ ) the operational lifetime of the device was determined.

\section{RESULTS}

We will deal first with the case of the open structure samples which were simply composed of a $40 \mathrm{~nm}$ thick $\mathrm{SiO}_{2}$ film grown on an Si substrate.

\section{Electron spin resonance}

The ESR spectrum of the vacuum annealed, (111) oriented wafer sample was composed of a single resonance peak characteristic of the Si dangling bond or $\mathrm{Pb}$ center [8]. By double numerical integration of the experimental derivative lineshape and comparison with the same 
double integral obtained for a reference sample (weak pitch) we ascertained that the $\mathrm{Pb}$ center density was $4 \times 10^{12} \mathrm{~cm}^{-2}$. Note that since the back face oxide on the Si wafer was not removed by etching, the actual single surface $\mathrm{Pb}$ center density is estimated to be $\sim 2 \times 10^{12} \mathrm{~cm}^{-2}$. This number is smaller than the maximum value observed by other authors [9] which is $\sim 10^{13} \mathrm{~cm}^{-2}$. The actual maximum one can obtain is not known and certainly depends upon oxidation conditions used during the growth of the oxide, etc. Furthermore, we do not exclude the possibility that some $\mathrm{Pb}$ center passivation occured between the time of manufacture and the time at which the experiments were carried out (about 7 days). This might be attributable, if real, to the absorption and reaction of atmospheric water vapor. We were unable to perform a complete systematic study of the evolution of the density of $\mathrm{Pb}_{b}$ centers in $\mathrm{H}_{2}$ and $\mathrm{D}_{2}$ annealed samples as a function of electron injection because of the weakness of the resonance signal (despite the use of noise averaging techniques). However, following electron injection for 600 minutes (corresponding, in this case, to an approximate total number of electrons of $2.2 \times 10^{16} \mathrm{~cm}^{-2}$ ) we observed $\mathrm{Pb}$ center densities of $\sim 6.5 \times 10^{11} \mathrm{~cm}^{-2}$, within experimental error we could detect no difference between the samples annealed in $\mathrm{H}_{2}$ or in $\mathrm{D}_{2}$. This value is 3 times smaller than the density observed in the vacuum annealed sample (which we assume to be the maximum value we can attain) but this may be due to the fact that we did not reach a saturation value of $H / D$ depassivation or because first order kinetics are operative and there is a finite probability that the $\mathrm{H}$ or $\mathrm{D}$ released during electron injection may re-passivate a dangling bond defect before the atoms have a chance to escape the oxide film or dimerise to form molecules.

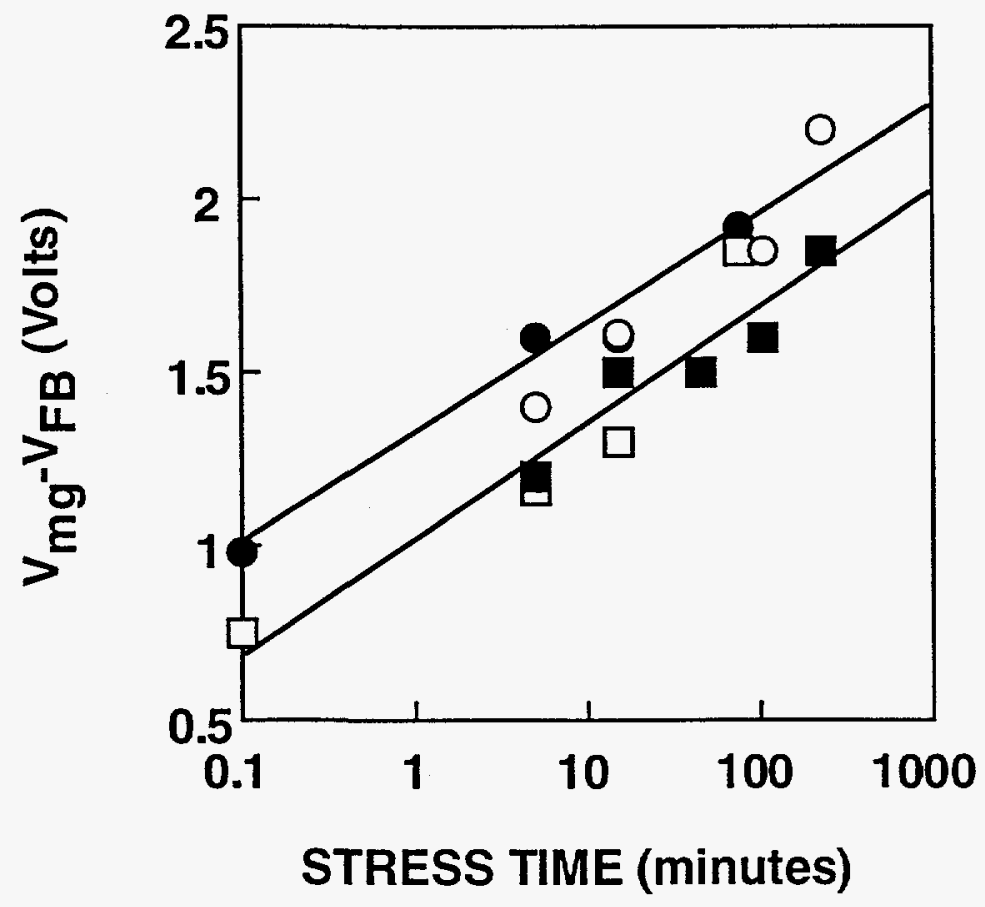

Figure 1. Variation of the mid-gap minus flat band voltages induced by electron injection into $\mathrm{H}_{2}(\bullet, O)$ and $\mathrm{D}_{2}(\square, \square)$ annealed $\mathrm{SiO}_{2} / \mathrm{Si}$ structures, the current was $\sim 10^{-7} \mathrm{~A} \mathrm{~cm}^{-2}$. The lines are least squares fits to the experimental data.

\section{Electrical capacitance/voltage measurements}

Open structure samples subjected to electron injection were also studied using standard capacitance/voltage measurement techniques. We assume that the density of interface states (Dit) may be determined from the experimental $\mathrm{C}(\mathrm{V})$ curve using the difference between the mid-gap voltage $\left(\mathrm{V}_{\mathrm{mg}}\right)$ and the flat-band voltage $\left(\mathrm{V}_{\mathrm{FB}}\right)[6]$. 
In Figure 1. we show the variation of $V_{m g}-V_{F B}$ as a function of electrical stress time for both $\mathrm{H}$ and $\mathrm{D}$ annealed samples. Although the samples were annealed identically the unstressed value of $\left(V_{m g}-V_{F B}\right)$ is slightly larger for the $\mathrm{H}$ annealed case. A stress time of 250 minutes corresponds to a total injected electron density of $\sim 10^{16}$ electrons $\mathrm{cm}^{-2}$. Despite imprecision in the experimental data, it appears that there is little difference in the time dependence (injected electron fluence) of the interface state density for the $\mathrm{H}_{2}$ and $\mathrm{D}_{2}$ annealed samples. The differences between the two straight lines is essentially due to a minor difference in the initial values of the interface state densities. The value of $V_{m g}-V_{F B}$ for the vacuum annealed sample was $1.5 \mathrm{~V}$ (corresponding to a value of $D_{\mathrm{it}} \sim 7.8 \times 10^{11} \mathrm{~cm}^{-2}$ basically integrated over $\sim 0.4 \mathrm{eV}$ of the total Si bandgap), this is smaller than that obtained for the $\mathrm{H}$ and $\mathrm{D}$ annealed samples following 250 minutes of stressing. This may evidence the fact that some passivation of interface states existed even in the vacuum annealed samples. Note that the density of $\mathrm{Pb}$ centers in the vacuum annealed samples was $2 \times 10^{12} \mathrm{~cm}^{-2}$ whilst the value of $D_{i t}$ is $7.8 \times 10^{11} \mathrm{~cm}^{-2}$ (integrated over $0.4 \mathrm{eV}$ of the bandgap). In the electrically stressed annealed samples, for the same stress, the value of $\mathrm{D}_{\mathrm{it}}$ approaches $10^{12} \mathrm{~cm}^{-2}$ whilst the density of $\mathrm{Pb}$ centers reaches $6.5 \times 10^{11} \mathrm{~cm}^{-2}$. The difference in these values suggests that defect centers other than the $\mathrm{Pb}$ are clearly present which contribute to $D_{i t}$.

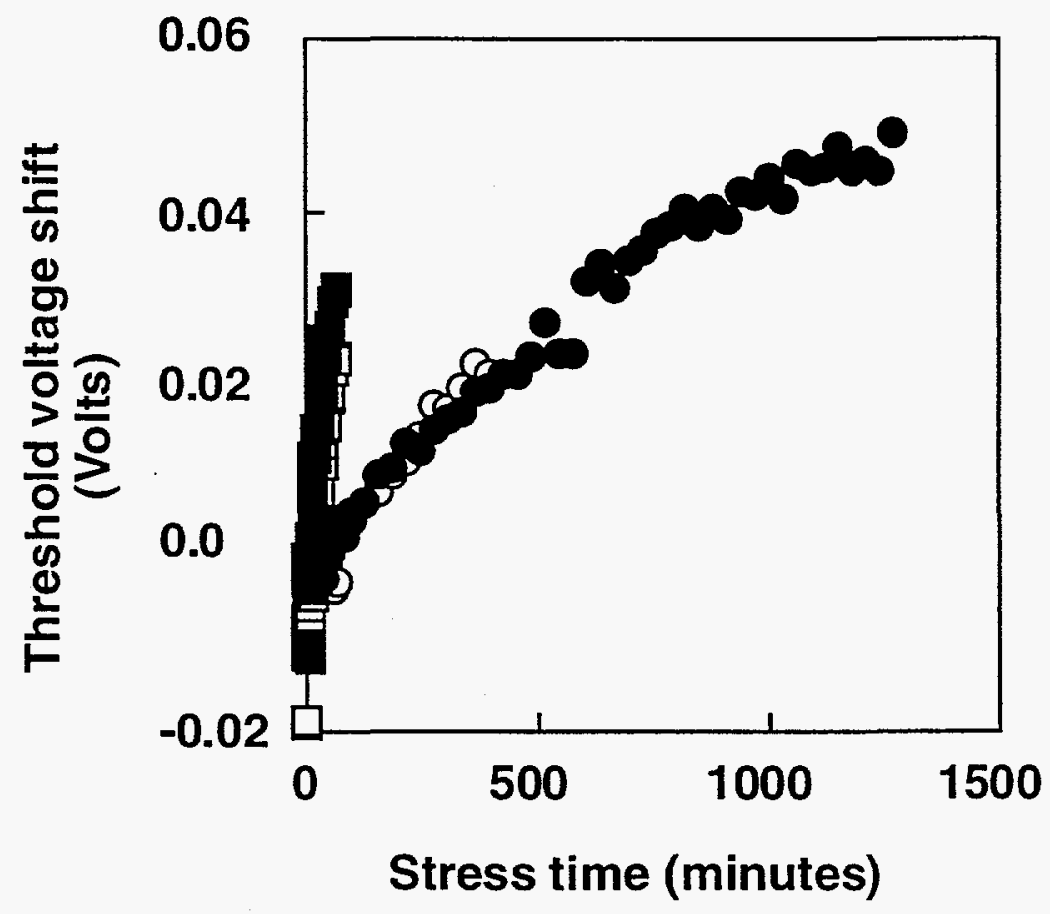

Figure 2. Threshold voltage shift as a function hot electron stress time for $0.25 \mu \mathrm{m}$ NMOS transistors with interfaces passivated with deuterium $(\bullet, 0)$ and with hydrogen $(\square, \square)$

\section{Hot electron injection induced degradation}

NMOS transistors were subjected to hot electron injection in the manner described in the experimental section. From the experimental plots of the lifetime for a $10 \%$ variation in $\mathrm{I}_{\mathrm{d}_{(i n)}}$ versus the reciprocal of the drain-source potential $\left(\mathrm{V}_{\mathrm{ds}}\right)$ we obtained projected lifetimes, $\tau$, at 2.5 $\mathrm{V}$ working potential of $\sim 12.6$ years for the devices annealed in $\mathrm{H}_{2}$ containing forming gas. The spread in $\tau$ values was rather small. For the devices annealed in $D_{2}$ containing forming gas the lifetime was 40 years $\leq \tau \leq 126$ years indicating an improvement of between 3 and 10 times. 
These values, though somewhat smaller, are consistent with those found by other workers [5] for larger devices. Note that other authors [5] have used the variation of the transconductance to ascertain the projected lifetime, using the same method we obtain values completely consistent with those determined via the $I_{d_{(l i n)}}$ variation method. In Figure 2 we show the variation of the device threshold voltage, $V_{t h}$, as a function of stress time whilst in Figure 3 we show the evolution of the channel transconductance, $\mathrm{gm}_{\mathrm{m}}$. In both cases drain-source stressing voltages $\left(\mathrm{V}_{\mathrm{ds}}\right.$ ) were 3.5 volts and the gate-source voltage $\left(\mathrm{V}_{\mathrm{gs}}\right)$ was the one corresponding to a maximum in the substrate current.

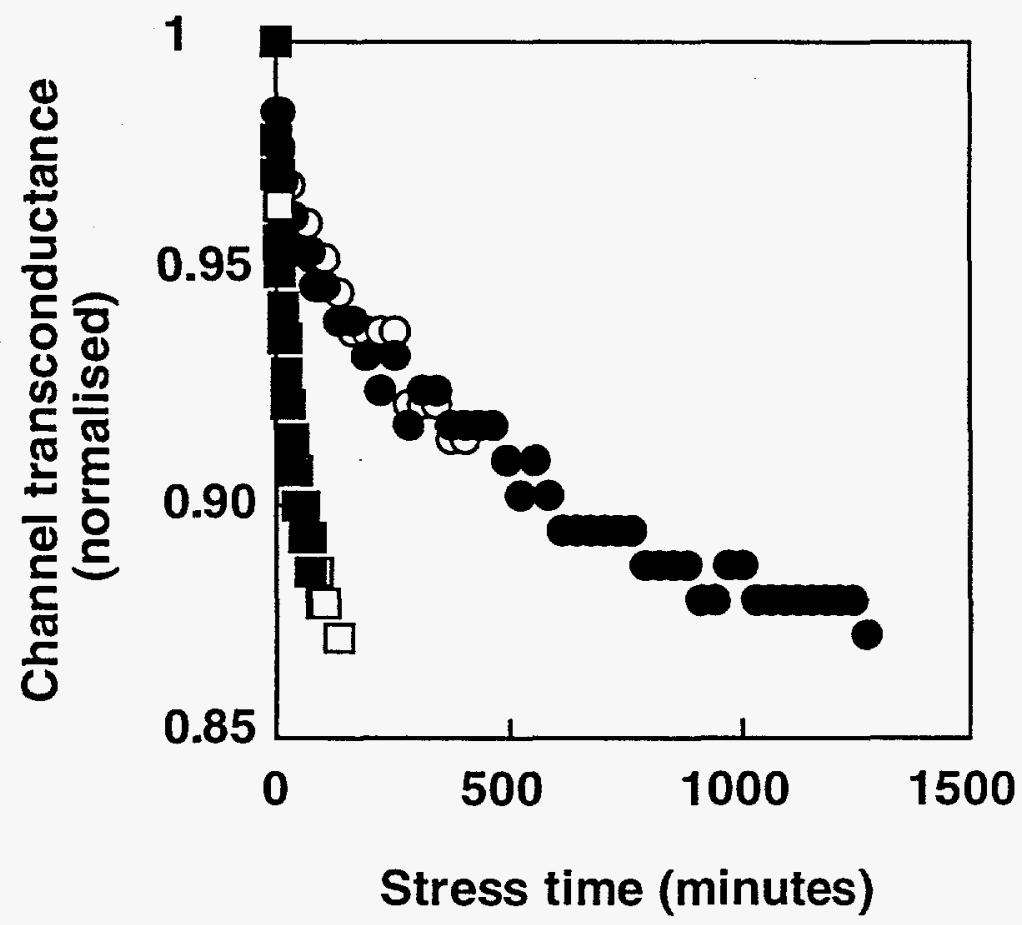

Figure 3. Variation of the channel transconductance with hot electron stress in $0.25 \mu \mathrm{m}$ NMOS transistors with deuterium $(\bullet, 0)$ and hydrogen $(\square, \square)$ passivated interfaces.

\section{DISCUSSION}

The density of states measurements on open structures, despite their limited precision, appear to suggest that the $H$ and $D$ annealed samples have similar sensitivity to the electron injection we have performed. This result contrasts dramatically with both the transistor data of other authors [5] and the transistor data we have obtained and presented here. The electrical results appear to agree more with the thermal desorption data obtained by Brower [1] using ESR to study the evolution of the $\mathrm{Pb}$ center density. Our ESR data is insufficiently precise to allow us to discern whether or not electron injection induced evolution of the $\mathrm{Pb}$ center density is different depending upon the gas used to perform the anneal prior to electron injection. The experiments on $0.25 \mu \mathrm{m}$ transistors presented here, clearly suggest that there are significant differences in the "hardness" to hot electron injection of the interfaces annealed in $\mathrm{H}$ or $\mathrm{D}$, the latter being less sensitive to degradation than the former.

We mentioned above that in general, and again consistent with the thermal desorption data [1], X-H and X-D bond energies are very similar so that one would not expect significant differences when measuring the activation energy for depassivation of $\mathrm{Si}-\mathrm{H}$ and $\mathrm{Si}-\mathrm{D}$ bonds. Furthermore, when the $H$ or $D$ is released, the only difference one would expect to observe is a $\sqrt{2}$ difference in diffusivity due to the mass difference. This factor should be present in the preexponential term and not in the activation energy. Mass like differences have been measured for 
the case of $\mathrm{H}^{+}$and $\mathrm{D}^{+}$diffusion [10] though the problem is complicated because the transport in the amorphous network is dispersive and does not follow a simple diffusional model.

In interpreting similar experiments performed on NMOS transistors, it has been suggested [11] that the origin of the difference in "hardness" to hot electron injection of $H$ and D passivated surfaces may be related to the close proximity of the bending mode frequency of the Si-D bond to a bulk phonon mode frequency in Si situated at $463 \mathrm{~cm}^{-1}$. Coupling between this phonon mode and the Si-D mode at $460 \mathrm{~cm}^{-1}$ is suggested to provide a relaxation channel which limits the ability to excite the Si-D bond by interaction with the injected electrons. The bending mode of the Si-H bond, situated at $637 \mathrm{~cm}^{-1}$, on the other hand is assumed to be sufficiently decoupled from the Si bulk phonon modes so that this bond can be more readily excited and desorption of the $\mathrm{H}$ occur. At the present time no other physical model, sufficient to explain the large observed differences between $\mathrm{H}$ and $\mathrm{D}$ passivated interfaces has been put forward. Although our transistor data, as the previous data [5] might be explained by such a model, it does not explain the difference we have observed for the electrical measurements on open structures passivated with $H$ and $D$. It must be underlined that in our experiments (as opposed to the hot electron injection experiments) the electrons were injected with the use of ultra-violet radiation. The energy supplied to the electrons in this case is essentially that required to inject them into the conduction band of the oxide ( $\sim 4 \mathrm{eV})$ but what energy they can impart to the $\mathrm{Si}-\mathrm{H}$ or $\mathrm{Si}-\mathrm{D}$ bond as compared to the case of hot electrons, is not clear.

Before concluding, it is perhaps worthwhile to make a few comments on the effects on $\mathrm{H}$ or $\mathrm{D}$ out-diffusion of confinement in $\mathrm{Si} / \mathrm{SiO}_{2} / \mathrm{Si}$ structures. We have previously demonstrated [12] that, in the case of high temperature annealing in $\mathrm{H}_{2}$ based forming gas, significant differences occur if one uses an open $\mathrm{SiO}_{2} / \mathrm{Si}$ structure as opposed to $\mathrm{Si} / \mathrm{SiO}_{2} / \mathrm{Si}$. Within a confined transistor gate structure, it is possible that the $\mathrm{D}$ or $\mathrm{H}$ released by electron injection behaves differently than in open structures where, for example, we assume that either the $\mathrm{H}$ or $\mathrm{D}$ can escape through the open surface once released. If we consider only the confined transistor structures then phenomena which also need to be considered include a) the probability that $H$ and $D$, when released, dimerise in the oxide to form "inactive" $\mathrm{H}_{2}$ and $\mathrm{D}_{2}$ and $\mathrm{b}$ ) the probability that a released $\mathrm{H}$ or $\mathrm{D}$ atom revisits the interface and passivates a dangling Si bond. A formalism which might be adapted to treat this problem has been discussed by Reed and Plummer [13] in the context of annealing induced passivation of Si dangling bonds. Basically, we can write two equations which take account of the variation of the concentration of dangling bonds, $\left[\mathrm{Si}^{\circ}\right]$, and the concentration of atomic $\mathrm{H}$ or $\mathrm{D},[\mathrm{H}]$.

$$
\begin{gathered}
\mathrm{d}\left[\mathrm{Si}^{\circ}\right] / \mathrm{dt}=\mathrm{k}_{\mathrm{O}}\left(\left[\mathrm{Si}_{\mathrm{o}}^{\circ}\right]-\left[\mathrm{Si}^{\circ}\right]\right)\left[\mathrm{e}_{\mathrm{inj}}\right]-\mathrm{k}_{1}\left[\mathrm{Si}^{\circ}\right][\mathrm{H}] \\
\mathrm{d}[\mathrm{H}] / \mathrm{dt}=\mathrm{k}_{\mathrm{O}}\left(\left[\mathrm{Si}^{\circ}{ }_{\mathrm{o}}\right]-\left[\mathrm{Si}^{\circ}\right]\right)\left[\mathrm{e}_{\mathrm{inj}}\right]-\mathrm{k}_{1}\left[\mathrm{Si}^{\circ}\right][\mathrm{H}]-2 \mathrm{k}_{2}[\mathrm{H}]^{2}
\end{gathered}
$$

where $k_{0}$ is a rate constant for creating Si dangling bonds by injected hot electrons $\left(e_{i n j}\right), k_{1}$ is the rate constant for passivation of dangling bonds by atomic $\mathrm{H}$ or $\mathrm{D}$ and $\mathrm{k}_{2}$ is a rate constant for dimerisation of atomic $\mathrm{H}$ or $\mathrm{D}$. [ $\mathrm{Si}^{\circ}{ }_{\mathrm{o}}$ ] is the maximum concentration of Si dangling bond sites which could be revealed if all the $H$ or D was removed. Since the equations are coupled, their solution is not a simple analytical problem. We expect, however, $\mathrm{k}_{1}$ and $\mathrm{k}_{2}$ to be different for $\mathrm{H}$ and $\mathrm{D}$ since they will involve the diffusivity of the atom concerned. Typically $\mathrm{k}_{\mathrm{X}} \propto \rho \mathrm{D}_{\mathrm{X}}$ where $\rho$ is a capture radius and $D_{X}$ the diffusivity of $H$ or $D$. One can see that a simple, intuitive prediction of how the $\mathrm{H}$ and $\mathrm{D}$ annealed samples will behave is not possible since the rate constants $\mathrm{k}_{1}$ and $\mathrm{k}_{2}$ both involve the diffusivity of the different species.

At the present time, the conclusions one must draw on the basis of the experimental data are that the improvement in the device lifetime induced by annealing in a D containing atmosphere instead of one containing $\mathrm{H}$ is of sufficient importance technologically that a much fuller understanding of the process of annealing induced "hardness" is needed. The differences we have observed when comparing the photo-injected electron induced behaviour for open structures with the hot electron injection in confined $\mathrm{Si} / \mathrm{SiO}_{2} / \mathrm{Si}$ structure require a much deeper understanding. 


\section{ACKNOWLEDGEMENTS}

The part of this work performed at Sandia National Laboratories was supported by the US Department of Energy under contract DE-AC04-94AL85000. Sandia is a multi-program laboratory operated by Sandia Corporation, a Lockheed-Martin company, for the US Department of Energy. The work carried out at the CNET was in the context of the GRESSI/ST joint development program. The deuterated forming gas was kindly supplied by Air Liquide (France).

\section{REFERENCES}

[1] K. L. Brower, Phys. Rev. B42 3444 (1990)

[2] J. H. Stathis, J. Appl. Phys. 776205 (1995)

[3] S. M. Myers, J. Appl. Phys. 615428 (1987)

[4] J. A. Kerr, in CRC Handbook of Chemistry and Physics (CRC Press, Boca Raton, Florida 1983) p F-176

[5] J. W. Lyding, K. Hess and I. C. Kizilyalli, Appl. Phys. Lett. 682526 (1996)

[6] L. M. Terman, Sol. State Electron. 3285 (1962)

[7] The $0.25 \mu \mathrm{m}$ MOSFETs were provided by SGS/Thomson, Crolles, France in the context of the GRESSI/ST joint development program.

[8] K. L. Brower, in The Physics and Chemistry of $\mathrm{SiO}_{2}$ and the Si-SiO2 Interface eds C. R. Helms and B. E. Deal (Plenum, NY 1988) p 309

[9] A. Stesmans and G. Van Gorp, Appl. Phys. Lett. 572663 (1990)

[10] N.Saks and R. W. Rendell, IEEE Trans. Nucl. Sci. NS39 2220 (1992)

[11] C. G. Van de Walle and W. B. Jackson, Appl. Phys. Lett. 69 (2441 (1996)

[12] K. Vanheusden, W. L. Warren and R. A. B. Devine, J. Non-Cryst. Solids (in press, 1997)

[13] M. J. Reed and J. D. Plummer, J. Appl. Phys. 635776 (1988) 